\title{
XXIV. Some experiments with the active deposit of thorium
}

\section{E. Marsden M.Sc. \& R.H. Wilson B.Sc.}

To cite this article: E. Marsden M.Sc. \& R.H. Wilson B.Sc. (1913) XXIV. Some experiments with the active deposit of thorium , Philosophical Magazine Series 6, 26:152, 354-361, DOI: 10.1080/14786441308634979

To link to this article: http://dx.doi.org/10.1080/14786441308634979

曲 Published online: 08 Apr 2009.

Submit your article to this journal

Џll Article views: 4

Q View related articles $\square$

Citing articles: 2 View citing articles 5 


\section{$\left[\begin{array}{ll}354 & ]\end{array}\right.$}

XXIV. Some Experiments with the Active Deposit of Thorium. By E. Marsden, M.Sci, Lecturer in Physics, and R. H. WiLson, B.Sc., University of Manchester *".

IN a recent paper Darwin and one of us $\dagger$ suggested the 1 following scheme for the transformations in the active deposit of thorium :-

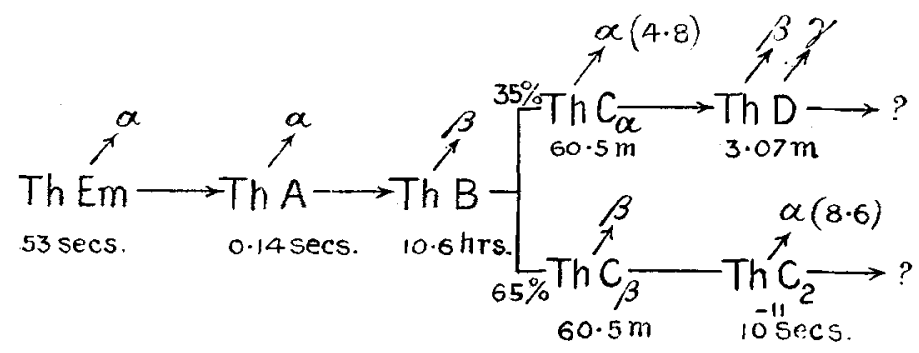

In this scheme $\mathrm{C}_{a} \ddagger$ and $\mathrm{C}_{\beta}$ were presumed to denote the same substance thorium $\mathrm{C}$ breaking down in different ways, i.e. with the expulsion of an $x$ or a $\beta$ particle. Miss Meitner $\S$, however, has obtained results which apparently show that the fraction of thorium $\mathrm{C}\left(i . e . \mathrm{C}_{a}\right)$ which gives rise to the $\gamma$-ray product $D$ can be isolated and separated from the rest of the products. In her experiments a hydrochloric acid solation of the active deposit, $\mathrm{B}+\mathrm{C}+\mathrm{D}$, was taken, a few drops of stannous chloride added, and suecessive nickel plates immersed for twenty minutes. The solution was then divided into two portions which were boiled to dryness on watch-glasses, and the variation of activity observed by $\alpha$ and by $\gamma$ rays, respectively, for the ensuing five hours. The results are shown in fig. 1 , where the curve marked $a$ gives the variation of the $x$-ray activity, and that marked $\gamma$ the variation of the $\gamma$-riay activity. With no stannous cbloride added, both the $\alpha$ - and the $\gamma$-ray curves rose together from the same small initial percentage of the maximum.

Since the $\gamma$ rays all come from thorium $D \|$, which in consequence of its short period practically accompanies $C_{a}$ in proportional amount, these results were interpreted by

* Communicated bv Prof. E. Rutherford, F.R.S.

+ Marsden \& Darwin, Proc. Roy. Soc. A. lxxxvii. p. 17 (1912).

I As we are only dealing with the thorium products they will in this paper be simply denoted by $\mathrm{A}, \mathrm{B}, \& \mathrm{c}$. When $\mathrm{C}$ is mentioned it will be taken to signify $\left(\mathrm{C}_{\alpha}+\mathrm{C}_{\beta}+\mathrm{C}_{2}\right)$.

\$ Lise Meitner, Phys. Zeitschr. xiii. p. 623 (1912).

il Except some soft $\gamma$ rays from B (see later). 
assuming that, in the presence of stannous chloride, the nickel plates remove the product $C_{\alpha}$ leaving $B$ and $C_{\beta}$ in solution. The initial $\alpha$-ray activity would thus be due to $\mathrm{C}_{2}$,

Fig. 1.

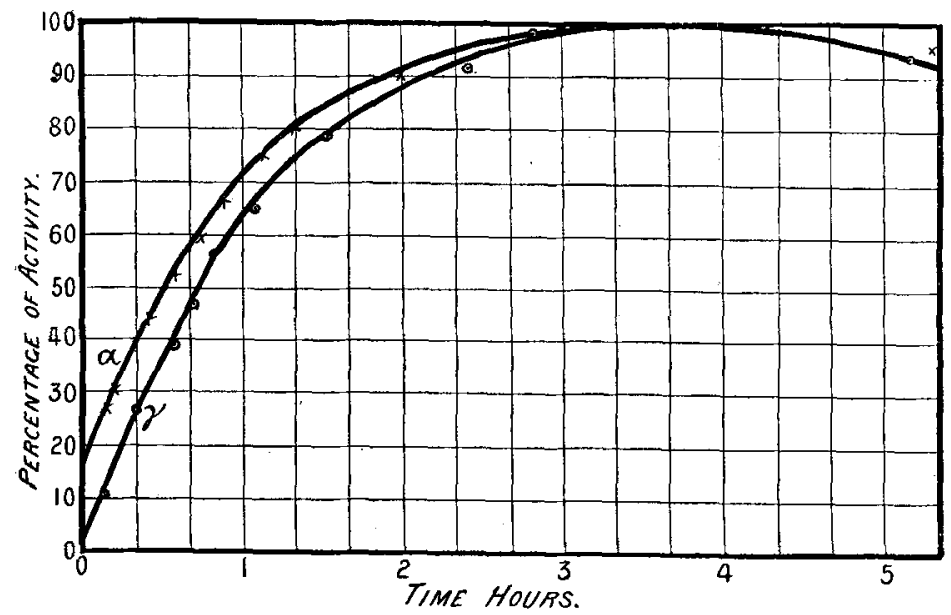

which is really part of $\mathrm{C}_{\beta}$ and has only been given the hypothetical period $10^{-11}$ second to conform to Geiger and Nuttall's law connecting the range of an $\alpha$ particle with the period of its products. The increase of activity would on this idea be due to the growth of $\mathrm{C}_{\alpha}$ and $\mathrm{D}$ in both cases.

In the experiments cited above, however, Marsden and Darwin showed that if thorium $\mathrm{C}$ consists of two separate products their periods must be the same to within about 2 per cent. The point of view taken was that for thorium ( there is a chance $\lambda_{a}$ that an atom should disintegrate in any second and give an $\alpha$ particle and a separate chance $\lambda_{\beta}$ that the same atom should disintegrate and emit a $\beta$ particle. This would require $0.65 \lambda_{a}=0.35 \lambda_{\beta}$ and $\lambda_{a}+\lambda_{\beta}=\lambda_{c}$; where $\lambda_{c}$ is the ordinary transformation constant of thorium $\mathrm{C}$ calculated from the period 60.5 minutes. If $\mathrm{C}_{a}$ and $\mathrm{C}_{\beta}$, or products corresponding to them, actually have an independent existence as Miss Meitner's experiment suggests, then it becomes of importance to ascertain the exact relation between their periods.

This was investigated as follows. A dilute hydrochloric acid solution of the active deposit was taken and a nickel plate dipped in for about one minute. In these circumstances the experiments of both Miss Meitner and 
Marsden and Darwin agree that amounts of $\mathrm{C}_{\alpha}$ and $\mathrm{C}_{\beta}$ are deposited on the plate in the same proportion as they exist in the active deposit as ordinarily collected. The ionizations due to the a particles of ranges $4.8 \mathrm{~cm}$. and $8 \cdot 6 \mathrm{~cm}$. were balanced against one another, as shown in fig. 2 .

Fig. 2.

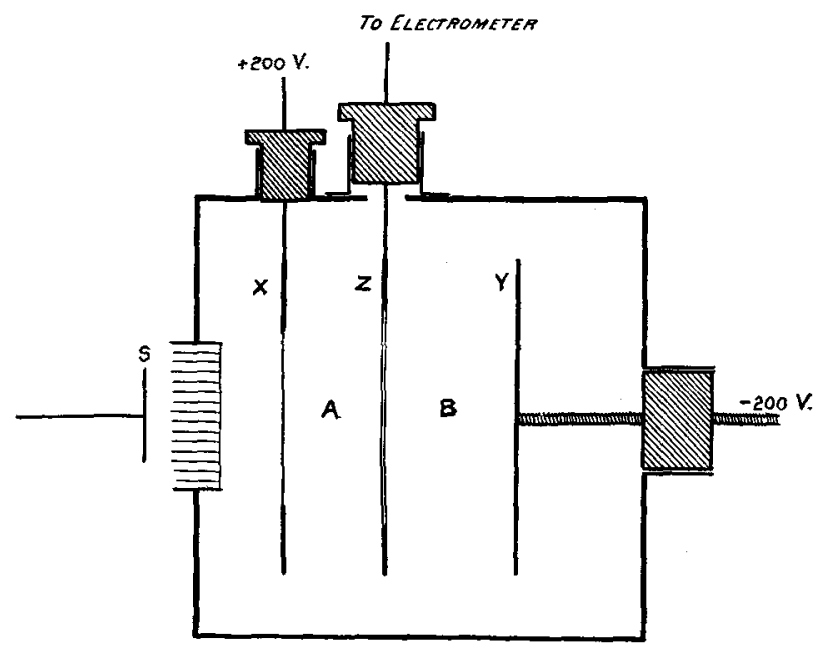

The a particles from the nickel plate $S$ passed through a canalising grid into two ionization chambers $A$ and $B$ of depth 2.0 and $2.6 \mathrm{~cm}$. respectively, the electrodes being rings covered with thin foils of aluminium equivalent to $0.5 \mathrm{~mm}$. of air in stopping power of a particles. The a particles of range $4.8 \mathrm{~cm}$. penetrated about $1.6 \mathrm{~cm}$. into the first chamber, whilst those of range $8.6 \mathrm{~cm}$. penetrated both chambers and struck the electrode $Y$ about $0.7 \mathrm{~cm}$. from the end of their range. $X$ was charged to +200 volts and $Y$ to -200 volts, whilst $Z$ was connected to a Dolezalek electrometer. Balance was made as accurately as possible by the adjustment of $\mathrm{S}, \mathrm{Z}$, and $\mathrm{Y}$.

In these circumstances it could be calculated that the ionization due to the a particles of range $4.8 \mathrm{~cm}$. was just about 50 per cent. of the total ionization in the first chamber. It was hoped to detect any difference in the periods by a change in the balance as the source decayed. A typical set of readings is given in Table $I$.

The first observation was made about twenty minutes after the nickel plate was withdrawn from the solution, so that the thorium $D$ was in equilibrium. Column I. gives the time 
interval between succeeding observations and this first observation. Column II. gives the deflexion of the electrometer-needle per minute as deduced from observations at

TABLE I.

\begin{tabular}{|c|c|c|c|}
\hline $\begin{array}{l}\text { Interval since } \\
\text { 1st observation. }\end{array}$ & $\begin{array}{l}\text { Drift of electrometer } \\
\text { needle. } \\
\text { cm. scale divs./min. }\end{array}$ & $\begin{array}{l}\text { Ionization in either } \\
\text { chamber. } \\
\mathrm{cm} \text {. scale divs./min. }\end{array}$ & $\begin{array}{l}\text { Percentage } \\
\text { disturbance } \\
\text { of balance. }\end{array}$ \\
\hline 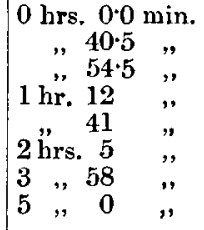 & $\begin{array}{l}-1 \cdot 3 \\
-0.3 \\
-0 \cdot 1 \\
-0.3 \\
-0 \cdot 2 \\
-0 \cdot 02 \\
-0.1 \\
-0 \cdot 1\end{array}$ & $\begin{array}{r}1400 \\
870 \\
740 \\
600 \\
430 \\
330 \\
90 \\
43\end{array}$ & $\begin{array}{l}-0 \cdot 1 \\
-0 \cdot 035 \\
-0 \cdot 015 \\
-0 \cdot 05 \\
-0 \cdot 04 \\
-0 \cdot 01 \\
-0 \cdot 12 \\
-0 \cdot 23\end{array}$ \\
\hline
\end{tabular}

intervals of one minute for five minutes. There were, of course, considerable probability fluctuations, but the mean position was taken in each case. Column III. gives the ionization in either chamber as deduced from the curve drawn through several observations as the decay proceeded. Column IV. gives the percentage disturbance of the balance. In these observations the barometric pressure and temperature were approximately constant during the experiment, otherwise a calculable correction would have been necessary owing to the alterations in the ranges of the $\alpha$ particles according to the density of the air.

It will be seen that the balance does not change by more than 0.3 per cent. in five hours. Therefore, since the $\alpha$ particles of range $4.8 \mathrm{~cm}$. contribute half the jonization in the first chamber the ratio of the numbers of particles of the two ranges does not alter by more than 0.6 per cent.

Taking the period of either product, say I., as 60.5 mins., i.e. $\lambda_{1}=0 \cdot 687$ hour $^{-1}$.

In 5 hours activity of $\mathrm{I}$. falls to a fraction $e^{-5 \lambda_{1}}$,

$$
\begin{aligned}
& \therefore \quad, 5, \quad, \quad \text { II. }, \quad, \quad, \quad e^{-5 \lambda_{1}} \times(1 \pm \cdot 006) \\
& =e^{-5 \lambda_{1}} \cdot e^{ \pm \cdot 006} \\
& =e^{-5\left(\lambda_{1} \pm \cdot 0012\right)} \text {. } \\
& \therefore \quad \lambda_{2}=\lambda_{1} \pm \cdot 0012 \\
& \lambda_{2}-\lambda_{1} / \lambda_{1}= \pm \cdot 0012 / 0 \cdot 687=1 / 570,
\end{aligned}
$$

i.e. the transformation constants are the same to within 1 part in 570. 
This agreement between the periods, which was verified in several sets of observations, is very remarkable if $\mathrm{C}_{\alpha}$ and $\mathrm{C}_{\beta}$ have an independent existence as different products, and is therefore strong evidence against that hypothesis.

Experiments were tried in which, before dipping in the nickel plate, a few drops of stannous chloride were added to the solution of the active deposit. Even in this case no change of balance with decay could be observed, and, moreover, keeping the electrodes in the same positions as before, the position of the source $S$ for a balance was exactly the same. As the balance was very sensitive to changes in the position of $\mathrm{S}$, this result shows that the proportion of the products on the nickel plate was exactly the same as when no stannous chloride was used.

Since this result is practically in direct opposition to the conclusion of Miss Meitner, a repetition of her experiments was undertaken. A hydrochloric acid solution of the active deposit was made, and, maintaining the temperature at about $90^{\circ}$ C., seven successive well-polished nickel plates were immersed for a period of twenty minutes in all. In this way the $\mathrm{C}$ product was nearly all removed and the $\mathrm{D}$ allowed to decay. A drop of the solution was taken and evaporated on either a plativum foil or a watch-glass for observations by $\alpha$ rays, and the remainder was quickly boiled to dryness for observations by $\gamma$ rays.

In the earlier experiments results were obtained exactly the same as those of Miss Meitner, i. e. the $\gamma$ and $\alpha$ ray activities rose proportionately, while when stannous chloride was added the $\gamma$-ray activity rose from a lower initial percentage value than the a-ray activity (see fig. 1).

Further investigation has, however, led us to the conviction that the results are anomalous, and caused mainly by the fact that in presence of hydrochloric acid thorium $C$ volatilizes at a comparatively low temperature. In the ordinary case of a plate exposed in air to thorium emanation, when presumably the products are present as oxides, $B$ is volatile at $700^{\circ} \mathrm{C} .^{*}$ and $\mathrm{C}$ at $1200^{\circ} \mathrm{C}$. If a hydrochloric acid solution of the active deposit is taken and boiled to dryness on a watch-glass and heated gently for about one minute, we find from the subsequent variation in activity with time that about 30 per cent. of the $\mathrm{C}$ is removed and practically none of the $B$. With a nitric acid solution, however, even with strong heating neither product is volatilized. If the hydrochloric acid solution bo taken, and

* Miss Slater, Phil. Mag. ix. p. 628 (1905). 
stannous chloride, zinc chloride, or even ammonium chloride added, and the solution boiled to dryness and heated as before, then practically the whole of the (? can be carried off by the fumes of the added salt. It would appear that the ( $)$ is carried off by some sort of mechanical action rather than by its forming compounds of increased volatility. In these experiments the temperatures were not measured accurately, but probably the highest temperature was from $250^{\circ} \mathrm{C}$. to $300^{\circ} \mathrm{C}$. in each case.

It appears probable that in Miss Meitner's experiment with stannous chloride the nickel plates remove only about 80 per cent. of the $\mathrm{C}$. When the resulting solution is heated the $a$-ray portion, which consists of only one drop, needs very little heating to boil it to dryness. The remainder, however, needs much more heating, due to its larger amount, and as volatilization is a time-effect, practically the whole of the remaining $($ ) is evaporated, so that the activity rises from zero. In the case when no stannous chloride is added, however, the nickel plates are more efficient in removing the C, due to there being no impurity present, and, moreover, if a small amount of $C$ is left it is not so volatile as when stannous chloride is present to carry it away.

We made observations of "rise curves" (see fig. 1) without evaporating the $\gamma$-ray portion to dryness, and found: that the $\alpha$ - and $\gamma$-ray activities rose proportionately. Further observations were made of the rise curves by $\alpha$ rilys, (1) with the source uncovered, and (2) with the source covered with foils sufficiently thick to absorb the a particles of short range. When reduced to the same maximum the curves showed no difference, indicating that no true separation of the products emitting the two sets of $\alpha$ particles had taken place. In another experiment a hydrochloric acid solution of the active deposit was taken and divided into two portions, to one of which a few drops of stannous chloride were added. On completely evaporating to dryness it was found that much more $C$ had been volatilized in the latter case than in the former.

In consideration of Miss Meitner's "rise curves" by $\alpha$ and $\gamma$ rays, moreover (fig. 1), it must be remembered that the $\gamma$ rays are emitted by $D$, which lags behind $C$, the origin of the $a$ rays. This is shown by the theoretical curves for $\mathrm{C}$ and $\mathrm{D}$, of which the initial parts are given in fig. 3 , the scale being such that the ordinates are percentages of the maximun activity in each case. It will be seen that D apparently rises from 6 por cent. below C.

An increased initial difference between the curves arises 
from the slow $\beta$ rays of $B$, which are intensely ionizing. With stannous chloride present as impurity, a larger amount of $B$ will be present for the same $\alpha$-ray activity due to the absorption in the material.

Fig. 3.

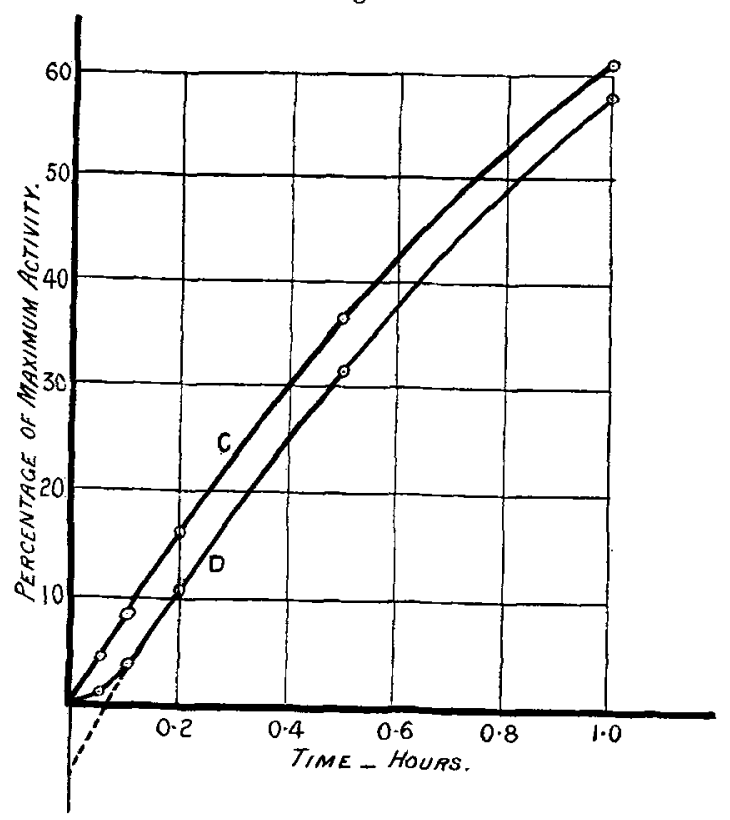

To throw further light on the possible separate existence of $\mathrm{C}_{\alpha}$ and $\mathrm{C}_{\beta}$, experiments were also made with $\beta$ rays. The $\beta$ rays of $\mathrm{C}_{\beta}$ have an absorption coefficient in aluminium of $13.5 \mathrm{~cm}^{-1}$ and those of $D 21.5 \mathrm{~cm}^{-1}$ Pure $C$ was deposited on a nickel plate by immersion in a hot dilute hydrochloric acid solution of the active deposit. The rise curves by $\beta$ rays due to the growth of D were determined, (1) when stannous chloride was added to the active deposit solution, and (2) with no stannous chloride. No difference could be detected. Furtber, after the $\mathrm{D}$ had attained equilibrium, $i$. e. about twenty minutes, the ratio of the $\beta$-ray activity tbrough $0.015 \mathrm{~cm}$. $A \mathrm{l}$ and $0.12 \mathrm{~cm}$. Al was measured in each case and found to be the same. Owing to the different absorption of the $\beta$ rays, this ratio would depend on the relative amounts of $\mathbf{D}$ and $\mathrm{C}_{\beta}$ present, and the result thus indicates no separation of $\mathrm{C}_{\beta}$ from the parent of $\mathrm{D}, i . e . \mathrm{C}_{a}$ on the above scheme. 
It is of course just possible that $D$ does not really arise from $\mathrm{C}_{\alpha}$, but from $\mathrm{C}_{\beta}$ or both. This, however, hardly seems likely.

From the various experiments we therefore conclude that Miss Meitner's experiments do not furnish sufficient evidence as to the existence of two separate products of about the same period in thorium $\mathrm{C}$, but that it is more probable that there are two methods of disintegration possible for the same atom.

\section{$\gamma$ Radiation from Thorium $B$.}

In the above experiments on the growth of $D$ from $B$ by Miss Meitner's method, it was noticed that when the $\gamma$-ray rise curves were determined through $1.6 \mathrm{~mm}$. and $7 \mathrm{~mm}$. lead, a difference in the initial percentage activity (of the maximum in each case) of about 11 per cent. was observed, the curve in the former case being the higher. This shows that soft $\gamma$ rays are emitted from $B$, and it will be noticed that they are very similar as regards penetrating power to the $\gamma$ rays from radium $B$. On account of these soft $\gamma$ rays all the measurements of $\gamma$ rays made in the above experiments were made through at least $7 \mathrm{~mm}$. lead.

Further experiments also showed that thorium $\mathrm{C}$ emits no appreciable quantity of $\gamma$ rays which can penetrate $1.6 \mathrm{~mm}$. lead. The properties of the various $\gamma$ rays are, however, being investigated in more detail by Prof. Rutherford and Mr. Richardson in this laboratory.

In conclusion, therefore, the following scheme represents our present knowledge of the transformations in the active deposit of thorium :

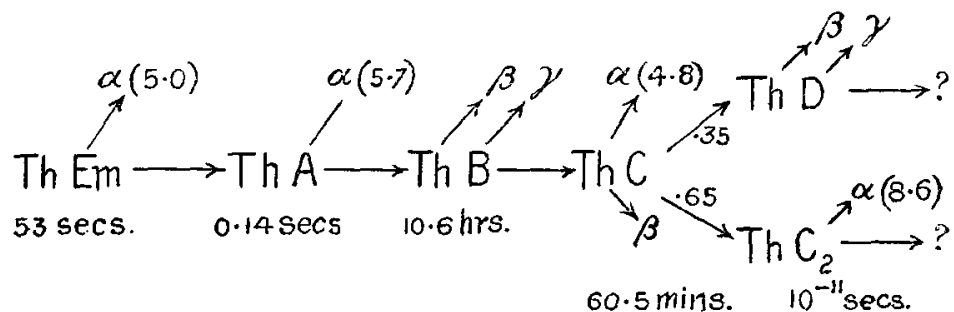

We are deeply indebted to Prof. Rutherford for his kind encouraging interest in these experiments. 